11 The International Committee of the Red Cross. Mines: a perverse use of technology. Geneva: International Committee perverse use of technology.
of the Red Cross, 1992.

12 Russbach R. Casualties of conflicts and mine warfare. In: Cahill KM, ed. A framework for survival. New York: Basic Books, and the Council on Foreign Relations 1993:121Books.

13 McGrath R, Stover E. Injuries from land mines. BMF 1991; 303:1492.

14 McGrath R. Trading in death: antipersonnel mines. Lancet 1993;342:628-9.
15 Asia Watch and Physicians for Human Rights. Landmines in Cambodia: the coward's war. New York: Asia Watch and Physicians for Human Rights, 1991.

16 Physicians for Human Rights. Hidden enemies: land mines in Northern Somalia. Boston: Physicians for Human Rights, 1992.

17 Human Rights Watch. Land mines in Angola. New York: Human Rights Watch, 1993.

18 Physicians for Human Rights. Landmines: a deadly legacy. New York: The Arms Project of Human Right's Watch and Physicians for Human Rights, 1993.

\title{
Incidence, pathology, and treatment of adder (Vipera berus L.) bites in man
}

\author{
C J Reading
}

The adder (Vipera berus) is the most widely distributed species of viper to occur in Europe. Its range extends north into the arctic circle and south to northwest Spain, northern Italy, and much of the Balkans. The distribution of the adder overlaps with that of at least three other species of viper in Europe, notably the Asp viper (Vipera aspis) in western and central Europe, the nose-horned viper (Vipera ammodytes) in the Balkans, and Orsini's viper (Vipera ursinii) in eastern Europe. Where overlap occurs there is considerable scope for the misidentification of snakes involved in cases of snake bite in man. However, in northern Europe and Scandinavia, the adder is the only venomous native snake and this problem does not arise.

In this review, published data from both the United Kingdom and northern Europe (including Scandinavia) are examined and considered alongside unpublished data obtained for Scotland, from many of the 14 regional health authorities (RHA) covering England and Wales, and from the National Poisons Information Service (NPIS) in London.

The adder or common viper ( $V$. berus)

The adder is the only venomous snake to occur naturally in the United Kingdom. It is a relatively small, thick bodied snake typically reaching a length of $65 \mathrm{~cm}$ as adults. ${ }^{1}$ Although very dark or even melanistic forms do occur, most adders have a clearly defined, dark, zig-zag stripe along the centre of the back. In females the background colour is often brown or reddish brown, whereas in males it is usually much paler (whitish/grey). Adders give birth to "live" young in late summer. At birth they have a length ${ }^{2}$ of $16-17 \mathrm{~cm}$ and have fully developed fangs and venom glands. The volume of venom that can be injected by a juvenile when biting is considerably less than the $10-18 \mathrm{mg}$ delivered in a typical bite from an adult. ${ }^{3}$

\section{Viper venom}

The venom is produced by modified salivary glands, stored in venom sacs which lie under and behind the orbit, and is injected $2-3 \mathrm{~mm}$ (subcutaneously) into the victim through the two enlarged, hollow and retractable fangs at the front of the mouth. However, the volume of venom delivered in a bite will vary and may be considerably less than the maximum possible for any individual snake if only one fang penetrates the victim. The venom of $V$. berus is a yellow liquid containing a complex mixture of high molecular weight proteins, mainly proteases, peptide hydrolases, hyaluronidase, and phospholipases whose effects are predominantly cytotoxic and haemorrhagic. ${ }^{45}$ The cytotoxic component attacks the vascular endothelial linings, typically resulting in early and extensive oedema and hypovolaemia. Systemic haemorrhage and coagulopathy appear to be rare in man, possibly because of the combination of relatively low venom potency and small delivered dose in a victim of relatively large body mass. Although it has not yet been isolated, there is some evidence that a cardiotoxic component is present in the venom causing $\mathrm{T}$ wave inversion, myocardial damage, ${ }^{6}$ and second degree heart block. ${ }^{7}$ Although now rare in the United Kingdom, death from adder envenoming can occur.

\section{Seasonality of adder bites in man}

The adder spends the winter months, typically mid-October to the end of February, in hibernation. ${ }^{2}$ However, in the south of the United Kingdom adders may emerge from hibernation as early as January and remain active until November. Adders are, however, usually at their most active during the period May to September but are more readily observed and encountered during the early spring.

Although adder bites in man have been recorded for each month from February to October, most recorded bites $(72.6 \%)$ occur during June, July, and August with a peak incidence $(33.2 \%)$ in July in the United Kingdom and Europe. ${ }^{45-15}$

\section{Frequency of adder bites in man}

Published reports provide information on cases of adder bite only where the victim presented to a general practitioner or hospital for treatment. The information is therefore biased and likely to underestimate the number 
Table 1 Number of adder bites reported annually in UK Regional Health Authorities under code E 905.0

\begin{tabular}{llll}
\hline RHA & Period (years) & $\begin{array}{l}\text { Mean No of } \\
\text { bites/year }\end{array}$ & Total \\
\hline South Western & $1982-91$ & 5.3 & 53 \\
North Western & $1990-91$ & 2.0 & 4 \\
West Midlands & $1987-91$ & 3.6 & 18 \\
$\begin{array}{l}\text { Oxford } \\
\text { South West }\end{array}$ & $1987-91$ & 0.4 & 2 \\
$\quad 1987-92$ & 4.8 & 29 \\
$\quad \begin{array}{l}\text { Thames } \\
\text { East Anglian }\end{array}$ & $1987-91$ & 3.2 & 16 \\
Wessex & $1991-92$ & 6.0 & 12 \\
Total & & 19.1 & 134 \\
\hline
\end{tabular}

of incidents of adder bite in man, while at the same time overestimating the severity of the effects of the bites (because victims with either very mild or no symptoms of envenoming will tend not to seek medical help). This view is supported by Marquart ${ }^{16}$ whose data, based on information provided by 182 doctors in Sweden, indicated that only one in 8.5 people bitten by an adder was admitted to hospital.

In the United Kingdom, Reid ${ }^{17}$ reported on 95 cases of adder bites in man occurring over the 100 years between 1876 and 1975. Many of these (around 50) were, however, those previously reported by Walker. ${ }^{11}$ Of the remaining 45 cases, 40 were ones with whose management Reid was personally involved (period: 1957-1975). This example and those of Hawley, ${ }^{5}$ reporting on 13 cases (two in Germany) in British Army personnel, and Wild, ${ }^{12}$ reporting on 16 cases in children admitted to Southampton hospital, highlight another problem associated with estimating the frequency of adder bites in the United Kingdom. This is that all those investigators reporting new cases did so using incidents from relatively small geographical locations, usually centred on one hospital. The problem is thus one of extrapolating from the local to the national scale. Furthermore, adders are not distributed evenly throughout the United Kingdom.

Between 1982 and 1990, 72 people (annual mean $=8.0 ; \mathrm{SD}=2.6 ; \mathrm{n}=9$ ) attended hospital in Scotland as a result of receiving an adder bite. During this period a peak in the number of reported adder bites occurred in July and August (54\%), with a secondary peak in May. The earliest reported bite was in February and the latest in October. The seasonal pattern of reported adder bites in Scotland is therefore similar to that for the rest of the United Kingdom and Europe. Although Scottish adder bite victims ranged in age between 1 and 77 years, they were predominantly (58\%) young males between the ages of 6 and 21 years, and only $12 \%$ of the reported cases were females. Although similar regional data for England and Wales are not readily available, those from seven RHAs (table 1) suggests that the reported incidence of adder bites in Scotland is relatively low when compared with the rest of the United Kingdom. For any given region or group of people within the United Kingdom the mean number of reported bites occurring annually varies between a minimum of 0.06 in central Scotland and a maximum of 8.0 for the whole of Scotland (table 2).

The highest number of adder bites treated in any year at one location was at Kingston hospital in the SW Thames RHA (1992) where five males and five females were treated for the effects of envenoming. This relatively low rate contrasts with the rate of about $400 /$ year indicated by Birch ${ }^{21}$ during the 1950 s. More recently, the NPIS in London (which recommends that all large accident and emergency (A\&E) departments should hold Zagreb antivenom) received $90-145$ inquiries/ year (1991-1994) concerning adder bite treatment from $A \& E$ departments and GPs (table 3).

The site of adder bites in victims

In a sample of 834 cases of adder bite in the United Kingdom, continental Europe, and Scandinavia (table 4) where the site of the bite was recorded, $89.8 \%$ occurred on the hand $(51.6 \%)$ and foot $(38.2 \%)$. Bites on the hand were usually on the thumb or fingers and often resulted from the person picking up a snake,

Table 2 Number of adder bites occurring at different locations within the UK over specified time periods. The British Army personnel were bitten at locations throughout England and Wales

\begin{tabular}{lllll}
\hline Author & No of cases & Period (years) & Location/data source & Mean No of bites/year \\
\hline Hawley $^{4}$ & 15 & $1983-87$ & Aldershot & 3.0 \\
Hawley $^{5}$ & 11 & $1979-88$ & British Army personnel & 1.1 \\
Holman and Evans $^{13}$ & 1 & 1978 & Devon & 1.0 \\
Moore $^{7}$ & 1 & 1987 & Swansea & 1.0 \\
Moran $^{18}$ & 10 & $1960-69$ & Bristol & 1.0 \\
Morton $^{19}$ & 18 & 8 & Cornwall & 2.2 \\
Prestt $^{20}$ & 3 & $1959-61$ & S Dorset & 8.0 \\
Reading (new data) $_{\text {(new data) }}$ & 72 & $1982-90$ & Scotland & 4.8 \\
(new data) & 29 & $1987-92$ & SW Thames RHA & 5.5 \\
(new data) & 53 & $1982-91$ & SW RHA & 3.6 \\
(new data) $_{\text {(new data) }}$ & 18 & $1987-91$ & WM RHA & 2.0 \\
(new data) $_{\text {(new data) }}$ & 2 & $1990-91$ & NW RHA & 0.3 \\
Reid $^{17}$ & 16 & $1987-92$ & Oxford RHA & 3.2 \\
& 12 & $1987-91$ & E Anglian RHA & 6.0 \\
& 95 & $1991-92$ & Wessex RHA & 0.95 \\
& $(55)$ & $1876-1975$ & UK & 0.6 \\
& $(40)$ & $1876-1971$ & UK-37 publications & 2.1 \\
Walker $^{11}$ & $(80)$ & $1957-75$ & Hospital cases & 0.8 \\
Wild $^{12}$ & $(9)$ & $1876-1975$ & England & 0.09 \\
\hline
\end{tabular}

RHA, Regional Health Authority. 
Table 3 The number of inquiries, concerning adder bites, made to the National Poisons Information Service in London 1991-1994. Data provided by A Campbell

\begin{tabular}{lllll}
\hline Source of enquiry & 1991 & 1992 & 1993 & 1994 \\
\hline $\begin{array}{l}\text { Accident and } \\
\text { emergency depts }\end{array}$ & 89 & 76 & 89 & 133 \\
$\begin{array}{l}\text { General } \\
\text { practitioners }\end{array}$ & 7 & 14 & 13 & 12 \\
$\begin{array}{l}\text { Veterinarians } \\
\text { General public }\end{array}$ & 13 & 10 & 11 & 23 \\
Miscellaneous & 6 & 1 & 1 & 1 \\
Total & 116 & 104 & 118 & 171 \\
\hline
\end{tabular}

while bites on the foot were most often on the ankle, and were the result of stepping on a snake. A reverse of this overall pattern was found in Sweden, ${ }^{8}$ where $64 \%$ of victims were bitten on the foot and only $34 \%$ on the hand. Two of the more bizarre cases were those of a baby boy (United Kingdom: 14 months) who was bitten on the ear as he lay in some grass ${ }^{12}$ and an eight year old boy (Sweden) bitten on the neck while swimming. ${ }^{8}$

\section{Age and sex of adder bite victims}

Men were more likely to be bitten than women or children, and incidents of adder bite have been recorded in people of all ages ranging from 1-78 years. ${ }^{7-91317182425}$ However, in children ( $<19$ years old) $59.6 \%$ of bites were received by those in the 5-14 year age group, with $66 \%$ of cases being boys.

\section{The severity and effects of adder bites in} man

Although most adder ( $V$. berus) bites result in trivial symptoms, envenoming can produce both local and systemic effects which can cause death from 6 to 60 hours after a bite, ${ }^{26}$ particularly in children and the elderly. ${ }^{27}$ The critical period for a victim is usually the first 12 hours after being bitten but may last for several days.

The proportion of adder bites occurring in each of Reid's five categories ${ }^{17}$ for cases reported from Switzerland, Sweden, and the United Kingdom are shown in table 5. The interpretation of these data requires care as only those of Persson and Irestedt ${ }^{8}$ and Stahel et al represent unbiased samples. The main conclusions that can be drawn are: (1) approximately $70 \%$ of reported adder bites result in either no or very mild effects; (2) deaths are rare.

The principal local effect of adder venom is oedema (sometimes massive), which may be delayed or occur within minutes but which is almost always present within two hours. Bruising also occurs and is usually most pronounced in the regions of the main lymphatic trunks and regional lymph nodes. Although the site of the bite is usually painful, pain may be minimal or absent. ${ }^{12}{ }^{17}$ During the first one to three days bruising and tenderness of the tissues increases in extent before slowly subsiding.

Hypotension is the most important sign of systemic envenoming, usually developing within two hours, and may be transient (resolving spontaneously within two hours), persistent, recurrent, or progressive and fatal. ${ }^{26}$

General effects of envenoming may start to appear within the first $10-20$ minutes after being bitten. ${ }^{23}$ Victims may feel faint, and children in particular may become drowsy or semiconscious. Nausea is usual and vomiting is a common and prominent feature which may last for several days. Diarrhoea may also occur. ${ }^{8}$ Other systemic effects, which may appear within five minutes or be delayed for many hours, and which may persist for up to 48 hours, include abdominal colic, incontinence of urine and faeces, sweating, vasoconstriction, tachycardia, and angio-oedema of the face, lips, gums, tongue, throat, and epiglottis, urticaria and bronchospasm. ${ }^{26}$ Additional features of envenoming include electrocardiographic $T$ wave inversion or flattening, ST elevation, second degree heart block and cardiac brady/tachyarrhythmias, atrial fibrillation, and myocardial infarction. ${ }^{26}$

Uncommon effects of envenoming include defibrinogenation or milder degrees of coagulopathy and spontaneous bleeding into the gastrointestinal tract, lungs, or urinary tract, coma and seizures secondary to hypotension or cerebral oedema, respiratory distress, pulmonary oedema, cerebral oedema, acute renal failure, cardiac arrest, intrauterine death, acute gastric dilatation, and paralytic ileus. ${ }^{26}$

Laboratory test results include neutrophil leucocytosis (>20 000/ $\mu \mathrm{l}$ in severe cases), thrombocytopenia, initial haemoconcentration and later anaemia resulting from extravasation into the bitten limb, and rarely haemolysis, elevation of serum creatine phosphokinase, and metabolic acidosis. ${ }^{26}$

\section{Treatment of and recovery from adder bites in man}

The effects of envenoming by the adder are unpredictable and therefore victims should be referred to hospital for monitoring.

\section{FIRST AID}

Immediately after an adder bite, the bite site should be immobilised to delay the spread of the venom. ${ }^{817}$ The bite area should not be manipulated or incised, as this may increase the rate of venom absorption, introduce infection, and aggravate local damage to the skin and underlying tissues. Similarly, potassium permanganate and ice packs (cryotherapy) should not be used, as these can promote local necrosis. The use of light bandaging or a ligature/tourniquet above the bite site is not recommended. Reassurance of the victim is important. ${ }^{17}$

\section{HOSPITAL MANAGEMENT}

Victims should continue to receive reassurance and be closely observed for at least two hours, with monitoring of blood pressure, pulse rate, respiratory rate, progression of local swelling, and new symptoms of envenoming. The bite site should be immobilised and antitetanus prophylaxis given. Asymptomatic cases with no local swelling after two hours may be discharged. Symptomatic cases should be monitored for a minimum of 24 hours and undergo investigations of white blood cell count, serum creatine phosphokinase and bicarbonate, and 
Table 4 Position of adder bites on the bodies of victims from the UK, Europe, and Scandinavia

\begin{tabular}{|c|c|c|c|c|c|c|c|c|c|c|c|c|}
\hline Author & 1 & 2 & 3 & 4 & 5 & 6 & 7 & 8 & 9 & 10 & 11 & 12 \\
\hline Borresen and Carlsen ${ }^{22}$ & 1 & 1 & & 1 & & & & & & & & \\
\hline Cederholm and Lennmarken ${ }^{23}$ & 1 & & & 1 & & & & & & & & \\
\hline Hawley $^{4}$ & 1 & & & 2 & & & & & & & & \\
\hline Hawley $^{5}$ & 1 & & & 10 & 2 & & & & & & & \\
\hline Holman and Evans ${ }^{13}$ & & & & 1 & & & & & & & & \\
\hline Moore $^{7}$ & & & & 1 & & & & & & & & \\
\hline Moran $^{18}$ & 6 & & & 4 & & & & & & & & \\
\hline Morton 19 & 3 & & & 9 & & & & & & & & \\
\hline Reid $^{17}$ & 21 & & & 61 & & & & & & & & \\
\hline Schiemenz and Biella ${ }^{24}$ & 142 & 47 & 10 & 180 & 12 & 6 & & 1 & & 1 & & \\
\hline Stahel et al & 37 & & & 69 & & & & & & & & \\
\hline Walker ${ }^{11}$ & 12 & & & 37 & & & & & & & & 1 \\
\hline Wild $^{12}$ & 7 & 1 & & 7 & & & & & & & 1 & \\
\hline Total (834) & 319 & 49 & 10 & 430 & 14 & 6 & 1 & 1 & 1 & 1 & 1 & 1 \\
\hline (\%) & 38.2 & 5.9 & 1.2 & 51.6 & 1.7 & 0.7 & - & - & - & - & - & - \\
\hline
\end{tabular}

1, Foot/ankle; 2, calf; 3, thigh; 4, finger/hand; 5, forearm; 6, upper arm; 7, shoulder; 8, chest; 9, neck; 10, nose; 11, ear; 12, brow.

Table 5 The severity of adder bites in man

\begin{tabular}{|c|c|c|c|c|c|c|}
\hline \multirow{2}{*}{ Author } & \multicolumn{6}{|c|}{ Severity of poisoning (after Reid[17]) } \\
\hline & $\overline{\mathrm{Nil}}$ & Mild & Moderate & e Severe & Fatal & Total \\
\hline Kaufmann $^{28}$ & 6 & 21 & 13 & 12 & 8 & 60 \\
\hline $\begin{array}{l}\text { Persson and } \\
\text { Irestedt }^{8}\end{array}$ & 37 & 62 & 21 & 16 & 0 & 136 \\
\hline Reid $^{17}$ & 3 & 36 & 12 & 29 & 15 & 95 \\
\hline Stahel et al & 13 & 62 & 24 & 14 & 0 & 113 \\
\hline Wild $^{12}$ & 3 & 6 & 5 & 2 & 0 & 16 \\
\hline Total $(420)$ & 62 & 187 & 75 & 73 & 23 & 420 \\
\hline$\%$ & 14.8 & 44.5 & 17.8 & 17.4 & 5.5 & \\
\hline Total $(249)^{\star}$ & $50^{\star}$ & $124^{\star}$ & $45^{\star}$ & $30^{\star}$ & $0^{\star}$ & $249^{\star}$ \\
\hline$\%$ * & $20.1^{\star}$ & $49.8^{\star}$ & $18.1^{\star}$ & $12.0^{\star}$ & $0^{\star}$ & \\
\hline
\end{tabular}

* Totals and percentages based on the data of Persson and Irest$\mathrm{edt}^{8}$ and Stahel et al ${ }^{9}$ only.

urinary and blood urea levels. Victims should also have an ECG twice daily or more often if hypotension persists.

Most cases of mild or moderate envenoming require no treatment other than symptomatic therapy, usually in the form of analgesics and antiemetics. Metoclopramide or chlorpromazine may be given for persistent vomiting, adrenaline and antihistamines (for example chlorpheniramine) initially for anaphylaxis and angio-oedema, and colloid for hypotension. In Sweden, Persson and Irestedt ${ }^{8}$ reported that cortisone was used extensively but concluded that its value was highly questionable. Antibiotics are not indicated.

Antivenom is indicated to prevent morbidity and reduce convalescence time in moderate to severe cases and to prevent death in severe cases. In the British National Formulary $(\mathrm{BNF})^{27}$ the indications for antivenom treatment include systemic envenoming, as indicated by hypotension, vomiting, haemostatic abnormalities, polymorphonuclear leucocytosis, and local envenoming if, within four hours of a bite on the hand or foot, swelling extends beyond the wrist or ankle. Zagreb antivenom should be given intravenously at a dose of two ampoules diluted with two to three volumes of normal saline and at a rate not exceeding $2 \mathrm{ml}$ of diluted antivenom per minute. The same dose should be used for both adults and children and can be repeated after one to two hours if there is no clinical improvement. ${ }^{27}$ Børresen and Wagner ${ }^{29}$ suggest that Zagreb antivenom should be administered within four hours in severe cases, if local reaction to the venom is to be limited to the affected limb.
This advice is also given in the $\mathrm{BNF}^{27}$ Persson and Irestedt $^{8}$ consider that Zagreb antivenom should only be used in cases of severe systemic poisoning when symptomatic treatment proves unsuccessful. Although a serum sensitivity test before giving the antivenom was not advocated by Reid, ${ }^{17}$ adrenaline should be immediately available if required. Reactions to Zagreb antivenom are very rare; however, victims with allergic histories or a history of hypersensitivity to equine antisera are at increased risk of developing severe antivenom reactions. They should therefore only be given antivenom if there are definite signs of severe systemic envenoming ${ }^{26}$, for example (1) a fall in blood pressure (systolic to $<80 \mathrm{~mm} \mathrm{Hg}$, or by more than $50 \mathrm{~mm} \mathrm{Hg}$ from the normal or admission value); (2) other signs of systemic envenoming including spontaneous bleeding, coagulopathy, pulmonary oedema or haemorrhage (shown by chest radiograph), ECG abnormalities, and peripheral leucocytosis $(>15000 / \mu \mathrm{l})$ and raised serum creatine kinase; (3) severe local envenoming - swelling of more than half of the bitten limb developing within 48 hours of the bite-even in the absence of systemic envenoming; (4) in adults, swelling extending beyond the wrist after bites on the hand or beyond the ankle after bites on the foot within four hours of the bite. (Antivenom should be given whenever there is evidence of systemic envenoming, even if its appearance is delayed for several days following a bite. ${ }^{26}$ )

In a retrospective study of 113 cases of adder bite (both V. berus and V. aspis) in Switzerland over a 16 year period, Stahel $e t a l^{9}$ reported that in 14 cases of severe envenoming (shock and angio-oedema of the tongue and lips) the median duration of hospital admission was reduced from 10 days in patients without antivenom treatment $(n=4)$, to five days in those receiving Zagreb antivenom $(n=10)$. In cases of moderate envenoming (vomiting, diarrhoea, cramps, hypotension, $\mathrm{n}=21$ ) or minor envenoming (local oedema only, $n=49$ ), antivenom treatment did not significantly affect the duration of a patient's stay in hospital, while in 11 victims with no signs of envenoming, the duration of hospital admission was increased from one day in six patients without antivenom to two days in five patients receiving treatment. They reported antivenom side effects including urticaria, angio-oedema, res- 
piratory distress, fever, and lymphadenopathy in four out of 49 victims.

Serum sickness may develop in a few cases one to two weeks after Zagreb antivenom use and is characterised by fever, urticaria, arthralgia, and albuminuria. The preferred treatment is oral corticosteroids (for example, prednisolone) at a dose of $5 \mathrm{mg}$ four times daily for five to seven days in adults and $0.7 \mathrm{mg} / \mathrm{kg} / \mathrm{d}$ for five to seven days in children in divided doses, together with an oral antihistamine (for example, chlorpheniramine) at a dose of $2 \mathrm{mg}$ four times daily for adults and $0.25 \mathrm{mg} / \mathrm{kg} / \mathrm{d}$ for children in divided doses. ${ }^{26}$

An affinity purified ovine antivenom (Fab monospecific "Beritab") has been specifically developed (Therapeutic Antibodies Inc) for the treatment of $V$. berus bites. It is, however, at present unavailable in the United Kingdom.

\section{Mortality resulting from adder bites}

Deaths resulting from adder bite are rare and less common now that in the past. For example, in Sweden ${ }^{8}$ between 1920 and 1950 there were 24 reported deaths, compared with only six between 1950 and 1980 . Similarly, in the United Kingdom the last death attributed to adder bite was of a five year old boy in Scotland in $1975 .^{14}$

\section{Conclusion}

Any victim of snake bite presenting to a general practitioner or hospital for treatment in the United Kingdom and northern Europe can be assumed to have been bitten by the adder ( $V$. berus), as this is the only naturally occurring venomous snake in these areas (although exceptionally "exotic" venomous snakes, kept as pets, may be responsible). However, in the United Kingdom, bites from non-venomous smooth snakes Coronella austriaca and grass snakes Natrix natrix may also occur rarely.

Although envenoming is a likely result of receiving a bite from an adder it is not inevitable, as "dry bites", in which no venom is injected, are known to occur in a number of tropical venomous snake species and may account for in excess of $50 \%$ of "accidental" bites in some species. ${ }^{30}$ Also, the quantity of venom injected can vary depending on the size of the snake, the efficiency of the bite, and the contents of the venom apparatus at the time of the bite. ${ }^{30}$ In addition, intraspecific variation in venom components within the geographical range of a species or between individuals in the same location has been demonstrated in snakes from Australia ${ }^{31}$ and the tropics, ${ }^{30}$ resulting in a range of effects of envenoming in snake bite victims. ${ }^{32}$ It is therefore likely that similar variations in the components of adder venom may also occur, resulting in unpredictable effects, thus underlining the need for adder bite victims to be monitored in hospital for a minimum of two hours following a bite.

The recommended protocol ${ }^{1326}$ for the treatment of adder ( $V$.berus) bite victims is that they should all be admitted to hospital and be observed and monitored for a minimum of two hours. Asymptomatic cases may then be discharged. Any victim showing any evidence of envenoming should continue to be observed and monitored for a minimum of 24 hours. This is very important in the case of children and the elderly, who are at particular risk from the effects of envenoming. Monitoring should include blood pressure, pulse and respiratory rates, the progression of local swelling and the appearance of new symptoms indicating, in particular, the onset of systemic envenoming (for example, hypotension). Zagreb antivenom should be given whenever there is any evidence of systemic envenoming or when local symptoms of envenoming are severe. During the administration of antivenom an injection of adrenaline should be immediately available for the treatment of anaphylactic antivenom reactions. Reassurance of a victim is an important aspect of adder bite treatment.

\section{Summary}

A review of published reports on the incidence, pathology, and treatment of adder (Vipera berus) bites in man in the United Kingdom and Europe produced numerous case studies but little information about the impact of adders as a threat to public health. Adder bites in man are not uncommon (at least 44/year and probably more than $90 /$ year in the United Kingdom) and, although they have been recorded for every month of the year between February and October, envenoming is most likely to occur during June, July, and August. Most adder bites are on the hand $(51.6 \%)$ or foot (38.2\%). The effects of adder bite envenoming are now known. Effective treatment protocols can reduce both the length of time victims spend in hospital and the morbidity in the affected areas; they have resulted in a decline in the death rate over the last 30 years, so that deaths are now rare.

This work was funded by Scottish Natural Heritage (SNH) and forms one part of a wide ranging contract investigating the status of the adder in Scotland. Significant clinical advice concerning the effects and treatment of envenoming by the adder wnD A Warrell at the Cen were A Tropical Medicine, John Radclife Hospital, Oxford. A Camp bell of the National Poisons Information Service in London received from S T Buckland, G M McGowan, S Gorzula, T Salter, B W Staines, and anonymous referees.

1 Arnold EN, Burton JA. A field guide to the reptiles and amphibians of Britain and Europe. London: Collins, 1978.

Smith M. The British amphibians and reptiles. London: Collins, 1951.

3 Theakston RDG, Reid HA. Effectiveness of Zagreb antivenom against envenoming by the adder, Vipera berus. Lancet 1976;ii:121-3.

4 Hawley A. Adder bites in Aldershot. $f$ R Army Med Corps $1988 \cdot 134: 135-7$.

5 Hawley A. Adder bites in the British Army, 1979-1988. $\mathcal{F} R$ Army Med Corps 1990;136:1 14-8.

6 Brown R, Dewar HA. Heart damage following adder bite in England. Br Heart $\mathcal{F}$ 1965;27:144-6.

7 Moore RS. Second degree heart block associated with envenomation by Vipera berus. Arch Emerg Med 1988;5: 116-8

8 Persson H, Irestedt B. A study of 136 cases of adder bite treated in Swedish hospitals during one year. Acta Med Scand 1981;210:433-9.

9 Stahel E, Wellauer R, Freyvogel TA. Envenomation due to indigenous snakes. Schweitz Med Wochenschr 1985;115 890-6.

10 Szyndlar, Z. Bites caused by the adder, Vipera berus (L.) in Poland. Przeglad Zool 1981;25:513-22.

11 Walker CW. Notes on adder-bite (England and Wales). $B M$ 1945;ii:13-14.

12 Wild RN. Adder bites in children. Arch Dis Child 1979;54:392-5

13 Holman HM, Evans R. An unusually early adder bite. Practitioner 1979;223:541-2.

14 Watson AA, Harland WA Adder bite fatality in Scotland. Med Sci Law 1977;17:190- 2. 
15 Arneil GC, MacLaurin JC. Case of adder bite with thrombosis of the saphenous vein. BMF 1961;i:1587-8. 16 Marquart H. Recherches statistiques sur les accidents par Marquart $\mathrm{H}$. Recherches statistiques sur les accidents par
morsures de serpents au Danemark et en Suède de 1900 à morsures de serpents au Danemark

7 Reid HA. Adder bites in Britain. BMF 1976;ii:153-6.

18 Moran CJ. Vipers and viper bites in the West Country. Bristol Med Chir ₹ 1970;85:3-6.

19 Morton TC. Adder bites in Cornwall. BMF 1960;ii:373-6. 20 Prestt I. An ecological study of the viper Vipera berus in southern Britain. F Zool Lond 1971;164:373-418.

21 Birch CA. Snake bite in Britain. Practitioner 1959;183:1058.

22 Borresen HC, Carlsen KH. Zagreb antiserum against envenomation by the adder, Vipera berus. Tidsskr Nor Laegeforen 1979;99:588-90.

23 Cederholm I, Lennmarken C. Vipera berus bites in children-experience of early antivenom treatment. Acta Paediatr Scand 1987;76:682-4.

24 Scheimenz $\mathrm{H}$, Biella $\mathrm{HJ}$. Accidents by stings of the common viper (Vipera b. berus L.) in the years 1955 to 1975 in viper (Vipera b. berus L.) in the years
Saxony. Zool-Abh (Dres) 1978;34:229-43

25 Hemmes GD. Viper bites in The Netherlands. Lacerta 1975;33:55-62.
26 Weatherall DJ, Ledingham JGG, Warrell DA (eds). Oxford textbook of medicine, 3rd ed. Oxford: Oxford University Press, 1996.

27 British national formulary. London: British Medical Association and Royal Pharmaceutical Society of Great Britain ation and Royal

28 Kaufmann C. Faelle von Schlangenbissen, die in der Schweiz beim Menschen zur Beobachtung gekommen sind. Corres-B1 Schweiz Aerzte 1892;22:689-96.

29 Børresen HC, Wagner K. Adder bites, lung injury and delayed infusion of Zagreb antivenom. Tidsskr Nor Laegeforen 1982;102:840-2

30 Warrell DA. In: Thorpe RS, Wuster W, Malhotra A, eds. Venomous snakes: ecology, evolution and snakebite. Symposium of the Zoological Society (London). Oxford: Oxford University Press (in press).

31 Williams V, White J. In: Thorpe RS, Wuster W, Malhotra A, eds. Venomous snakes: ecology, evolution and snakebite. Symposium of the Zoological Society (London). Oxford: Oxford University Press (in press)

32 Theakston RDG. In: Thorpe RS, Wuster W, Malhotra A eds. Venomous snakes: ecology, evolution and snakebite. eds. Venomous snakes: ecology, evolution and snakebite. Oxford University Press (in press)

\section{Septic and non-septic olecranon bursitis in the accident and emergency department - an approach to management}

\author{
Accident and \\ Emergency \\ Department, Guy's \\ Hospital, St Thomas \\ Street, London SE1 \\ 9RT, United Kingdom \\ I M Stell \\ Correspondence to: \\ Dr I M Stell. \\ Key terms; bursitis \\ olecranon bursitis; \\ Staphylococcus aureus \\ NSAIDs \\ Accepted for publication \\ 15 May 1996
}

Olecranon bursitis is a relatively common problem presenting to accident and emergency (A\&E) departments. One third of cases are likely to be septic. The remainder are referred to in this paper as non-septic olecranon bursitis, which includes the cases sometimes termed traumatic or idiopathic olecranon bursitis. Occasional cases are related to rheumatoid arthritis or gout. As the clinical diagnosis can be difficult, septic cases are often not diagnosed; treatment with anti-inflammatory agents alone then leads to a delay in diagnosis and worsening suppuration. Incision and drainage can often be avoided by initial aspiration and antibiotics.

In this paper I discuss the aetiology of these conditions, the various tests which can identify the septic cases, the treatment options, and finally suggest an approach to management in A\&E.

\section{Epidemiology}

The overall incidence of olecranon bursitis is not known. The vast majority of cases are seen in males, typically aged $30-60$ years.

\section{Aetiology}

In non-septic olecranon bursitis, inflammation arises either because of bleeding into the bursa, or through the release of inflammatory mediators following trauma. ${ }^{12}$ This inflammation can lead to permanent damage to the epithelial lining of the bursa, predisposing to repeated attacks in the future.

In septic olecranon bursitis, trauma, breaks in the skin, or foci of infection provide a portal of entry from which bacteria appear to migrate across soft tissues to enter the bursa. ${ }^{34}$ However, there is not always a good history of trauma, so penetration through minute breaks in the skin must occasionally happen. Haematogenous spread does not appear to be the usual route of infection. ${ }^{5}$ Ninety per cent of aspirates cultured reveal Staphylococcus aureus, and most of the remainder are infected with $\beta$ haemolytic streptococci. ${ }^{6-8} \mathrm{~A}$ range of more unusual organisms-Gram positive and Gram negative bacteria, mycobacteria, and fungihave been identified in infected olecranon bursae, frequently in the context of systemic diseases. There is evidence that many of these are spread by the haematogenous route. ${ }^{5}$

About one third of septic olecranon bursitis cases have a history of a previous episode of olecranon bursitis. It may be that in these cases the fibrosis and distortion of vascular architecture from previous inflammation prevents the bursa from dealing efficiently with foreign material, such as bacteria. ${ }^{2}$ The olecranon bursa has a relatively poor blood supply, which is in contrast to the synovial membranes of joints. ${ }^{9}$ This may, in part, explain why septic olecranon bursitis is much commoner than septic arthritis. The bursal membrane is biologically different from that of joints. ${ }^{410}$

Impaired immunity is an important aetiological factor in up to half of all septic cases. The most common reason is alcohol abuse, but steroids, diabetes, renal impairment, and malignancy are also responsible. ${ }^{11}$

\section{Presenting features}

The onset of symptoms can be over several hours or several days. The degree of inflamma- 